\title{
Genetic and Biochemical Analysis of Mutants Affected in Nitrate Reduction in Rhizobium meliloti
}

\author{
By GYƠRGY B. KISS, ÉVA VINCZE, ZSUZSA KÁLMÁN, \\ TAMÁS FORRAI AND ÁDÁM KONDOROSI \\ Institute of Genetics, Biological Research Center, Hungarian Academy of \\ Sciences, H-6701, Szeged, P.O. Box 521, Hungary
}

(Received 17 October 1978; revised 8 December 1978)

\begin{abstract}
Twenty-five mutants unable to utilize nitrate as sole nitrogen source were isolated from Rhizobium meliloti 41. These mutations mapped at four different sites, $\operatorname{nar} A, \operatorname{nar} B, \operatorname{nar} C$ and nar $D$; nar $B, C$ and $D$ were located between $\operatorname{trp}-15$ and ade-15 on the chromosome. Nar $A$ mutants were affected in assimilatory nitrate reduction but not in 'respiratory' nitrate reduction and had methyl viologen-coupled nitrate reductase activity. $N a r B$ mutants were affected in both assimilatory and 'respiratory' nitrate reduction and lacked methyl viologen-coupled nitrate reductase activity. $\operatorname{Nar} C$ and narD mutants were impaired not only in assimilatory and 'respiratory' nitrate reduction but lacked xanthine dehydrogenase activity as well. Acid-treated crude extracts of these two mutant classes were unable to restore NADPH-coupled nitrate reductase activity to the nit-I mutant of Neurospora crassa, indicating the lack of active molybdenum cofactor. All mutants tested were effective in symbiotic plant tests and had normal nitrogenase activity, indicating that nitrogenase and nitrate reductase do not share the same molybdenum cofactor.
\end{abstract}

\section{INTRODUCTION}

Nitrogenase, nitrate reductase and xanthine dehydrogenase all contain a molybdenum cofactor (Pateman et al., 1964; Bulen \& LeComte, 1966; Nason et al., 1970; Pienkos et al., 1977). Nif genes of Klebsiella pneumoniae, introduced into Escherichia coli K12, are poorly expressed at low concentrations of molybdate if the host carries certain nitrate reductase mutations (chlD) (Kennedy \& Postgate, 1977; Skotnicki \& Rolfe; 1977). This indicates that nitrogenase and nitrate reductase share some molybdenum-processing functions. It is the purpose of the present study to explore the possibility of such a relationship in Rhizobium meliloti.

Although the acid-released Mo cofactor of Rhizobium japonicum nitrogenase component I could replace the cofactor of the nitrate reductase system of Neurospora crassa (Nason et al., 1971), these two enzyme systems may not be closely related. Shah \& Brill (1977) isolated an iron-molybdenum (FeMo) cofactor from component I of nitrogenase of a number of organisms, and Pienkos et al. (1977) showed that nitrate reductase could not be complemented in vitro with the FeMo cofactor but only with the Mo cofactor isolated from xanthine oxidase. Thus nitrogenase and nitrate reductase do not share the same molybdenum cofactor.

Rhizobium meliloti $41(\mathrm{Rm} 41)$ possesses nitrogenase, nitrate reductase and xanthine dehydrogenase, and so is suitable for studying the common involvement of the Mo cofactor. In $\mathrm{Rm} 41$, nitrate reduction can be detected in vivo under different physiological conditions (Sik \& Barabás, 1977). Assimilatory nitrate reduction is observed only in bacteria grown on nitrate as sole nitrogen source; those grown on complete medium also exhibit very high 
nitrate reductase activity at the end of the exponential growth phase. In keeping with the terminology for nitrate reduction systems of other organisms, the latter activity is referred to as 'respiratory' nitrate reduction. It is likely that the 'respiratory' and assimilatory functions are only properly attributable to a more or less complete enzyme 'system' probably comprising a complex of more than one enzyme, plus associated electron transport mechanisms.

Based on the two types of nitrate reduction in $\mathrm{Rm} 41$, at least two different approaches can be applied to obtain mutants lacking the ability to reduce nitrate. The first approach was to look for and isolate mutants of $\mathrm{Rm} 41$ defective in 'respiratory' nitrate reduction (Kondorosi et al., 1973). Several of these were ineffective in symbiosis but were still able to assimilate nitrate as the sole nitrogen source (Sik \& Barabás, 1977). For our second approach, to select mutants completely devoid of nitrate reduction, we developed a procedure for isolating mutants unable to assimilate nitrate as sole nitrogen source. In this paper we describe the isolation, properties and mapping of such mutants of $\mathrm{Rm} 41$ and their effects on 'respiratory' nitrate reduction, xanthine dehydrogenase and symbiotic nitrogen fixation. Part of this work has been previously presented (Kiss et al., 1977).

\section{METHODS}

Micro-organisms. These are listed in Table 1.

Media and bacterial growth. Basal medium contained (per litre): $\mathrm{K}_{2} \mathrm{HPO}_{4}, 0.1 \mathrm{~g} ; \mathrm{NaCl}, 1 \mathrm{~g}$; Tris, $3 \mathrm{~g}$; $\mathrm{MgSO}_{4} .7 \mathrm{H}_{2} \mathrm{O}, 246 \mathrm{mg} ; \mathrm{CaCl}_{2}, 11 \mathrm{mg} ; \mathrm{FeCl}_{3} .6 \mathrm{H}_{2} \mathrm{O}, 0.27 \mathrm{mg} ; \mathrm{Na}_{2} \mathrm{MoO}_{4} .2 \mathrm{H}_{2} \mathrm{O}, 0.242 \mathrm{mg} ; \mathrm{H}_{3} \mathrm{BO}_{3}, 3 \mathrm{mg}$; $\mathrm{MnSO}_{4} .4 \mathrm{H}_{2} \mathrm{O}, 2.23 \mathrm{mg} ; \mathrm{ZnSO}_{4} .7 \mathrm{H}_{2} \mathrm{O}, 0.287 \mathrm{mg} ; \mathrm{CuSO}_{4} .5 \mathrm{H}_{2} \mathrm{O}, 0.125 \mathrm{mg} ; \mathrm{CoCl}_{2}, 0.065 \mathrm{mg}$; biotin, $2 \mathrm{mg}$. GTS medium was basal medium supplemented with (per litre): glucose, $2 \mathrm{~g}$; sodium succinate, $2 \cdot 7 \mathrm{~g}$. GTS/glutamate medium was basal medium supplemented with (per litre): glucose, $10 \mathrm{~g}$; sodium succinate, $2.7 \mathrm{~g}$; sodium glutamate, $1 \mathrm{~g}$; yeast extract (Difco), $10 \mathrm{mg}$. $\mathrm{FNO}_{3}$ medium was basal medium supplemented with (per litre): fumaric acid, $2 \mathrm{~g} ; \mathrm{NaNO}_{3}, 0.85 \mathrm{~g}$. HYP medium was basal medium supplemented with hypoxanthine $\left(\mathrm{g} \mathrm{l}^{-1}\right)$. Complete medium was GTS medium supplemented with (per litre): yeast extract (Difco), $1 \mathrm{~g}$; Bacto-tryptone (Difco), $10 \mathrm{~g} ; \mathrm{NH}_{4} \mathrm{Cl}, 100 \mathrm{~g}$. The $\mathrm{pH}$ of all media was adjusted to $7 \cdot 5$. Solid media contained $2 \%$ (w/v) agar (Difco). For $\mathrm{FNO}_{3}$ plates, Bacto-agar was washed three times with distilled water before use. All chemicals were of analytical grade and were not further purified. The concentration of various nitrogen sources added to different media is indicated in the text.

Bacterial strains were maintained in $20 \%(\mathrm{v} / \mathrm{v})$ glycerol at $-20{ }^{\circ} \mathrm{C}$. Strains were recovered by 50 -fold dilution of the stock culture into complete medium and aerated at $34^{\circ} \mathrm{C}$ or by streaking directly on to complete plates for single colonies and incubated for $2 \mathrm{~d}$ at $34^{\circ} \mathrm{C}$. Overnight cultures were started from these cultures by 50 -fold dilution or by suspending the bacteria with a wire loop in complete medium and grown with aeration at $34^{\circ} \mathrm{C}$. Growth of bacteria was followed turbidimetrically by measuring the $A_{540}$.

Mutagenesis and selection for mutants. $N$-Methyl- $N$ '-nitro- $N$-nitrosoguanidine (NTG; Koch-Light) mutagenesis was carried out as described previously (Kondorosi et al., 1973). After mutagenesis, cells were washed with saline/phosphate, suspended in complete medium and grown to allow segregation and phenotypic expression of recessive alleles, then washed again and passed twice in GTS medium supplemented with $\mathrm{NH}_{4} \mathrm{Cl}\left(1 \mathrm{mg} \mathrm{ml}^{-1}\right)$. Diluted samples containing about 100 bacteria were spread on to $\mathrm{FNO}_{3}$ agar plates and incubated in a bag flushed with ammonia-free air. After $3 \mathrm{~d}$, small transparent colonies were picked as putative nitrate non-utilizing mutants.

Determination of nitrate reductase activity. Nitrate reductase activity was determined by measuring the amount of nitrite formed. The nitrate reductase activity in intact bacteria was determined as follows: $1 \mathrm{ml}$ samples were removed and flushed with argon for $30 \mathrm{~s}$; the reastion was then started by adding $\mathrm{NaNO}_{3}$ (10 mM final concentration) and terminated by adding the nitrite reagent described below. Nitrite formation was linear at least up to $15 \mathrm{~min}$. Exposure of the reaction mixtures to air instantly stopped nitrite production.

Methyl viologen-coupled activity was determined in bacteria treated with cetyltrimethylammonium bromide (CTAB). CTAB $\left(0 \cdot 1 \mathrm{mg} \mathrm{ml}^{-1}\right)$ was added to the bacterial suspensions and agitated vigorously for $3 \mathrm{~min}$. Bacteria were then centrifuged at $4{ }^{\circ} \mathrm{C}$ washed with reaction mixture [reaction mixture was $50 \mathrm{~mm}$ $\mathrm{KH}_{2} \mathrm{PO}_{4} / \mathrm{KOH}$ buffer, $\mathrm{pH} 7 \cdot 3$, containing $\mathrm{NaNO}_{3}\left(0.85 \mathrm{~g}^{-1}\right)$ and methyl viologen $\left.\left(0.1 \mathrm{~g}^{-1}\right)\right]$, resuspended in $1 \mathrm{ml}$ of reaction mixture and stored at $0{ }^{\circ} \mathrm{C}$ for $1 \mathrm{~d}$. To determine nitrate reductase activity, $4.95 \mathrm{ml}$ of appropriately diluted CTAB-treated suspension was pipetted into a test tube and flushed with argon for $30 \mathrm{~s}$. The reaction was started by adding $0.05 \mathrm{ml}$ of freshly prepared sodium dithionite solution $\left(250 \mathrm{mg} \mathrm{Na} \mathrm{S}_{2} \mathrm{~S}_{4}\right.$ 


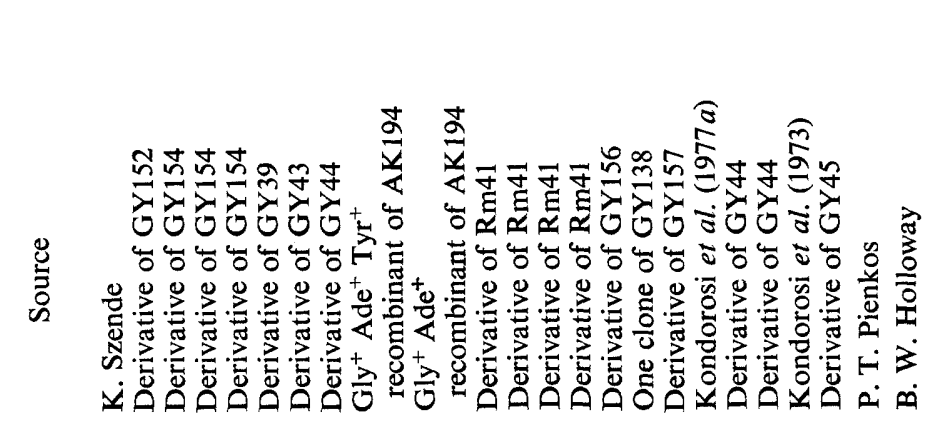

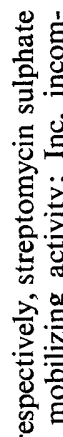

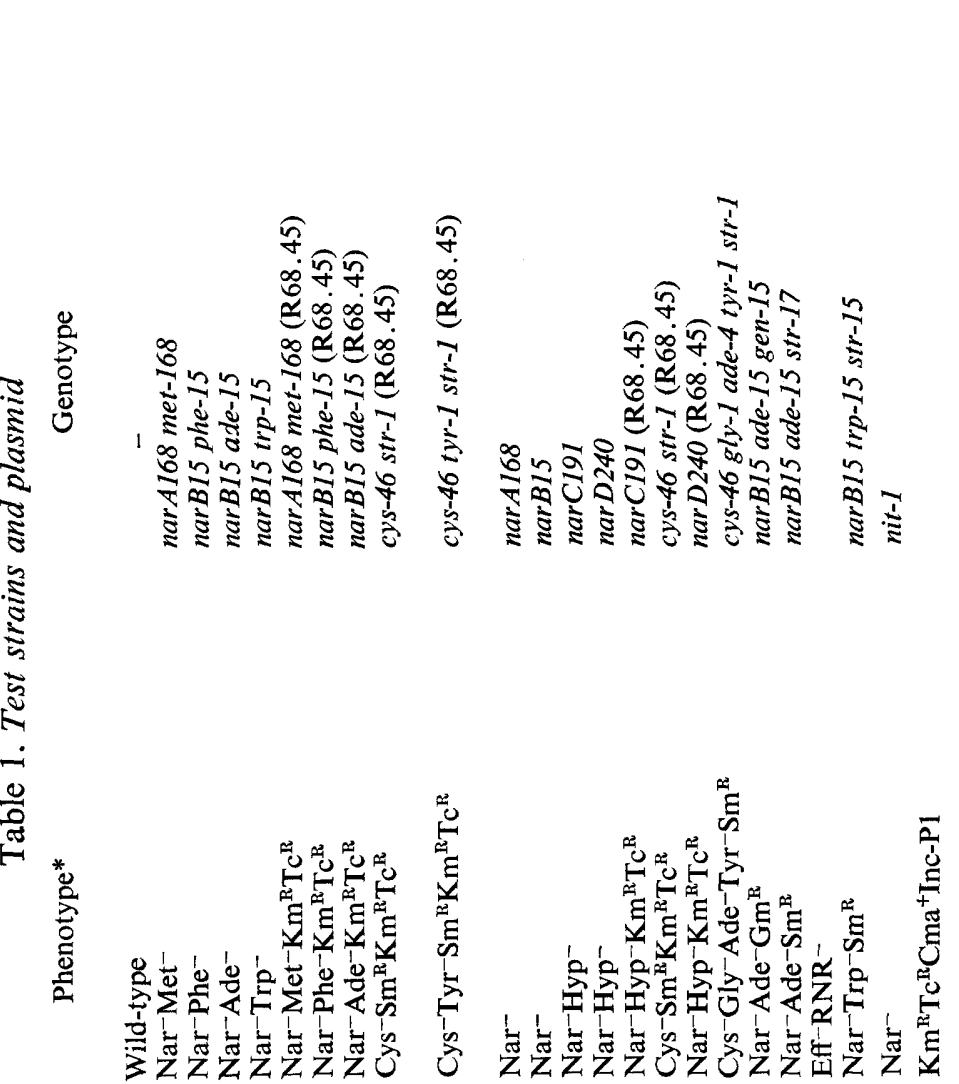

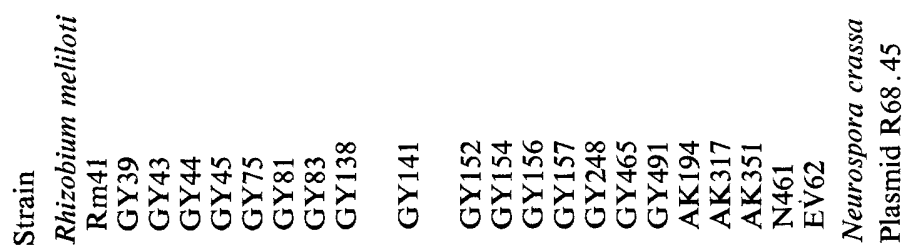


in $10 \mathrm{ml}$ of reaction mixture free of oxygen) and conducted at $30^{\circ} \mathrm{C}$ in open test tubes under a stream of argon. Samples $(1 \mathrm{ml})$ were removed at different times and the dithionite was oxidized by vigorous agitation to complete the reaction. Nitrite measurement showed linear production for at least $1 \mathrm{~h}$. One unit of enzyme activity was defined as the amount of protein producing $1 \mathrm{nmol}$ nitrite $\min ^{-1}$ at $30^{\circ} \mathrm{C}$; the specific activity was expressed as enzyme units per mg protein. No nitrite reductase activity could be detected under any of the conditions employed.

Nitrite assay. The amount of nitrite was determined spectrophotometrically by a procedure modified from that of Nicholas \& Nason (1957). Freshly prepared Griess-Ilosvay reagent $(0.5 \mathrm{ml})$ was added to $1.0 \mathrm{ml}$ of the sample to be tested. (Griess-Ilosvay reagent contained equal volumes of $1 \%(\mathrm{w} / \mathrm{v})$ sulphanilic acid dissolved in $30 \%(\mathrm{v} / \mathrm{v})$ acetic acid and $0.3 \%(\mathrm{w} / \mathrm{v})$ 1-naphthylamine in $30 \%(\mathrm{v} / \mathrm{v})$ acetic acid.) After 10 min, the mixture was centrifuged and the $A_{540}$ was measured.

Protein determination. Protein was determined by the method of Lowry et al. (1951) as modified by Hartree et al. (1972). This procedure could also be applied to whole cell suspensions with good reproducibility. Bovine serum albumin (Sigma) was used as standard.

Polyacrylamide gel electrophoresis. Electrophoresis under non-denaturing conditions was carried out in $7.5 \%(\mathrm{w} / \mathrm{v})$ polyacrylamide gel at $\mathrm{pH} 8.5$ according to Davis (1964). Cell-free extracts were prepared by sonicating the cells for 15 periods of $30 \mathrm{~s}$ each at maximum output (MSE ultrasonic disintegrator). The crude homogenates were centrifuged at $4{ }^{\circ} \mathrm{C}$ for $20 \mathrm{~min}$ at $35000 \mathrm{~g}$ and the supernatants were dialysed overnight against distilled water. Samples ( $200 \mu \mathrm{g}$ protein) in $20 \%(\mathrm{w} / \mathrm{v})$ sucrose were loaded on the gels and run at $3 \mathrm{~mA}$ per gel until the tracking dye reached the bottom of the gel column. Gels were tested for enzyme activities and stained for protein with $1 \%(\mathrm{w} / \mathrm{v})$ Coomassie Brilliant Blue R-250 in propan-2-ol/acetic acid $(2 \cdot 5: 1, \mathrm{v} / \mathrm{v})$ and destained with $10 \%(\mathrm{v} / \mathrm{v})$ acetic acid.

Gels were developed for xanthine dehydrogenase activity according to the method of Mendel \& Müller (1976). For identification of nitrate reductase, gels were kept in nitrate-free reaction mixture supplemented with $\mathrm{Na}_{2} \mathrm{~S}_{2} \mathrm{O}_{4}\left(25 \mathrm{mg} \mathrm{ml}^{-1}\right)$ for $10 \mathrm{~min}$ and then transferred into reaction mixture free of methyl viologen. At the position of nitrate reductase the dark-blue gel became transparent.

Complementation test. Neurospora crassa mutant strain nit-1 was grown in Fries medium containing $\mathrm{NH}_{4} \mathrm{Cl}$ and transferred to medium containing $\mathrm{NaNO}_{3}$ to induce synthesis of nitrate reductase (Pienkos et al., 1977). Hyphae were broken in $0 \cdot 1 \mathrm{M}-\mathrm{KH}_{2} \mathrm{PO}_{4} / \mathrm{KOH}$ buffer, $\mathrm{pH} 7 \cdot 2$, containing $5 \mathrm{~mm}-\mathrm{EDTA}, 1 \mathrm{~mm}-$ phenylmethylsulphonyl fluoride, $1 \mathrm{~mm}-\mathrm{NADPH}$ and $1 \%(\mathrm{w} / \mathrm{v}) \mathrm{NaCl}$, by homogenization with sand at $4{ }^{\circ} \mathrm{C}$, then centrifuged at $30000 \mathrm{~g}$ for $30 \mathrm{~min}$. Crude extracts $\left(9 \cdot 2\right.$ to $17.0 \mathrm{mg}$ protein $\left.\mathrm{ml}^{-1}\right)$ of wild-type and nar mutants grown in complete medium till late-exponential phase were prepared as described for gel electrophoresis. Acid-treated crude extracts were prepared as reported by Nason et al. (1971), except that the reagents used were flushed with argon and acid treatment was carried out under an argon atmosphere. Cell-free extract $(0.25 \mathrm{ml})$ of nit $-1\left(11.4 \mathrm{mg}\right.$ protein $\left.\mathrm{ml}^{-1}\right)$ was incubated with $0.5 \mathrm{ml}$ of acid-treated crude extracts of nar mutants for $30 \mathrm{~min}$ at room temperature. Nitrate reductase activity was then assayed with NADPH and FAD as electron donor and carrier (Pienkos et al., 1977). The nitrite formed was measured as described before.

Test of effectiveness. Plant nodulation experiments were carried out with lucerne(Medicago sativa) seedlings as described previously (Kondorosi et al., 1977b).

Mating experiments. Mating conditions in all experiments were as described before (Dixon et al., 1976; Kondorosi et al., 1977a). Selection for hypoxanthine utilization was carried out on HYP plates.

\section{RESULTS}

\section{Two types of nitrate reduction in Rhizobium meliloti 41}

Before isolating mutants of $\mathrm{Rm} 41$ defective in nitrate reduction, the physiological conditions for distinguishing the two different activities were established.

Assimilatory nitrate reduction. Rm41 grew in GTS/glutamate medium with a doubling time of about $4 \mathrm{~h}$. If ammonium, nitrate or hypoxanthine were added, the generation time decreased to about $2 \mathrm{~h}$. Assimilatory nitrate reduction could be demonstrated in GTS/ glutamate medium after addition of nitrate by following the accumulation of nitrite (Fig. 1). The total nitrate reductase activity was presumably higher than that of nitrite reductase; therefore we could observe nitrite accumulation. Added nitrite was taken up by the culture. Chloramphenicol abolished both the accumulation and consumption of nitrite, indicating that after addition of nitrate or nitrite, de novo protein synthesis was necessary for the 


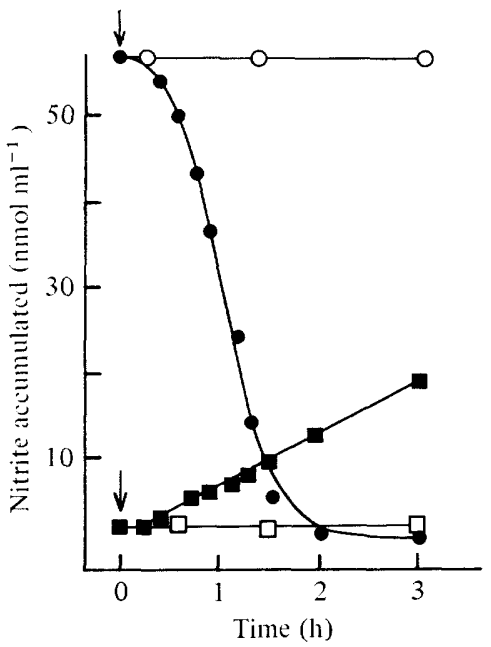

Fig, 1

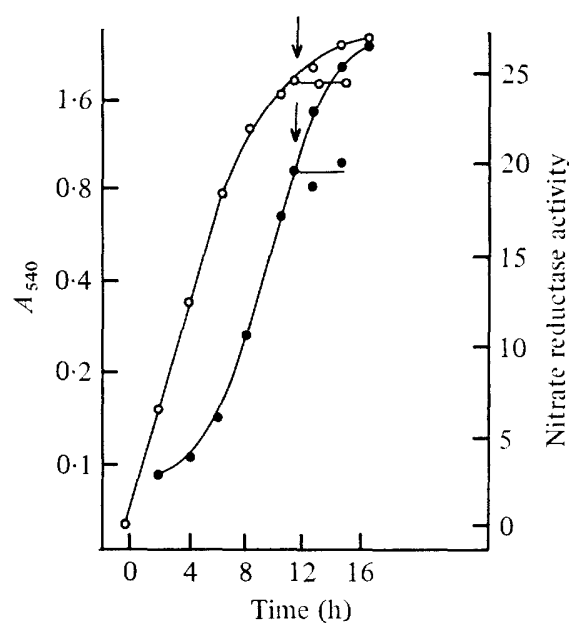

Fig. 2

Fig. 1. Detection of assimilatory nitrate and nitrite reduction. Rm41 was grown in GTS/glutamate medium with aeration at $34^{\circ} \mathrm{C}$ to $1 \times 10^{8}$ cells $\mathrm{ml}^{-1}$, then divided into four subcultures and incubated further. Samples were removed at different times and nitrite was determined immediately as described in Methods. The following compounds were added at the time indicated by the arrows: $\mathrm{KNO}_{2}(\mathrm{O}) ; \mathrm{KNO}_{2}$ and chloramphenicol or $\mathrm{NH}_{4} \mathrm{Cl}(\mathrm{O}) ; \mathrm{NaNO}_{3}(\boldsymbol{\square}) ; \mathrm{NaNO}_{3}$ and chloramphenicol or $\mathrm{NH}_{4} \mathrm{Cl}(\square)$. $\mathrm{KNO}_{2}, \mathrm{NaNO}_{3}$ and $\mathrm{NH}_{4} \mathrm{Cl}$ were added at $10 \mathrm{~mm}$ and chloramphenicol at $200 \mu \mathrm{g} \mathrm{ml}^{-1}$.

Fig. 2. Induction of 'respiratory' nitrate reduction in complete medium. Rm41 was grown in complete medium with aeration at $34^{\circ} \mathrm{C}$ to about $1 \times 10^{7}$ to $5 \times 10^{7}$ cells $\mathrm{ml}^{-1}$ and samples were removed at different times. Cell density $\left(A_{540} ; O\right)$ and nitrate reductase specific activity $(O)$ in intact bacteria was determined as described in Methods. A high degree of dilution was necessary to eliminate the residual nitrate reductase activity from overnight (stationary phase) cells. Chloramphenicol $\left(200 \mu \mathrm{g} \mathrm{ml}^{-1}\right)$ was added at the time indicated by the arrows.

formation of functional assimilatory nitrate and nitrite reduction systems. These reductions also failed to function in the presence of ammonium.

'Respiratory' nitrate reduction. $\mathrm{Rm} 41$ also exhibited nitrate reduction at the end of the exponential phase in complete medium without added nitrate (Fig. 2). In these conditions we could measure the nitrate reduction by following the accumulation of nitrite because no nitrite reduction could be detected. Nitrate reduction could be assayed in whole cells under anaerobic but not under aerobic conditions. If chloramphenicol was added, neither cell growth nor further induction of nitrate reduction took place.

\section{Isolation of mutants affected in assimilatory nitrate reduction (Nar-)}

We were unable to isolate mutants affected in nitrate reduction on the basis of chlorate resistance because Rm41 cannot grow anaerobically and, furthermore, growth was not inhibited by chlorate in any of the media tested. However, cells could grow on minimal GTS agar plates without added combined nitrogen almost as well as on a medium supplemented with $\mathrm{NH}_{4} \mathrm{Cl}\left(1 \mathrm{mg} \mathrm{ml}^{-1}\right)$. Pagan et al. (1977) found the same phenomenon with cowpea strain $32 \mathrm{H} 1$ (Rhizobium sp.) and concluded that cells can scavenge combined nitrogen from the agar and ammonium from the atmosphere. To overcome this, we used $\mathrm{FNO}_{3}$ plates for isolating mutants. If nitrate was omitted from this medium the wild-type colonies were smaller and more transparent than the colonies growing on nitrate. We expected that the colonies of the $\mathrm{Nar}^{-}$mutants would have the same phenotype on $\mathrm{FNO}_{3}$ medium as those of the wild-type on $\mathrm{FNO}_{3}$ medium without nitrate. Taking advantage of this system, we have isolated $36 \mathrm{Nar}^{-}$mutants from seven independent experiments. The 


\section{Table 2. Growth of mutants in liquid media containing various nitrogen sources}

Overnight cultures were diluted in saline to about $1 \times 10^{3}$ to $5 \times 10^{3}$ cells ml-1;0.1 ml samples of these suspensions were added to $5 \mathrm{ml}$ of GTS liquid medium supplemented with the different nitrogen sources (each at $1 \mathrm{mg} \mathrm{ml}^{-1}$ ). After $3 \mathrm{~d}$ incubation with aeration at $34^{\circ} \mathrm{C}$, the $A_{540}$ was measured.

\begin{tabular}{lcccccc} 
& \multicolumn{5}{c}{ Nitrogen source } \\
Strain & None & $\mathrm{NaNO}_{3}$ & $\mathrm{NH}_{4} \mathrm{Cl}$ & Xanthine & $\begin{array}{c}\text { Hypo- } \\
\text { xanthine }\end{array}$ & Uric acid \\
Rm41 & 0.32 & 1.32 & 1.68 & 1.53 & 1.56 & 1.40 \\
GY152 & 0.36 & 0.39 & 2.35 & 1.68 & 1.95 & 1.80 \\
GY154 & 0.40 & 0.38 & 2.90 & 1.75 & 1.75 & 1.55 \\
GY156 & 0.21 & 0.20 & 2.25 & 0.37 & 0.19 & 1.35 \\
GY157 & 0.37 & 0.33 & 2.20 & 0.34 & 0.35 & 1.90
\end{tabular}

mutants were cultured in minimal liquid media containing nitrate and nitrite, respectively, and tested for growth and production or consumption of nitrite as described for the wild-type bacteria in the legend to Fig. 1. On this basis, the isolates were divided into two groups: nitrate non-utilizers (25 isolates) and nitrite non-utilizers (11 isolates). Biochemical and genetic analyses (see below) revealed that the 25 nitrate non-utilizing mutants could be grouped into four classes. One representative of each class (GY152, GY154, GY156 and GY157) was selected for further study.

\section{Growth of mutants on different nitrogen sources}

Several mutations might be expected to give rise to a nitrate non-utilizing phenotype. For example, one might obtain mutations in structural, regulatory or transport genes for the nitrate reductase system or in genes determining the Mo cofactor of nitrate reductase, or pleiotropic regulatory mutations affecting the utilization of various nitrogen sources. Therefore, we tested the mutants for growth on media containing different nitrogen sources (Table 2). All mutant types grew more heavily in media with histidine, proline, glutamine, asparagine and urea as sole nitrogen sources (data not shown). Mutants were also tested for growth on media supplemented with the intermediates of the purine catabolic pathway. Representatives of two mutant groups (GY156 and GY157) did not grow on xanthine and hypoxanthine but did grow on uric acid as sole nitrogen source (Table 2). Since the enzyme xanthine dehydrogenase is responsible for the oxidative degradation of both xanthine and hypoxanthine, the growth properties of these two mutants suggested that xanthine dehydrogenase and nitrate reductase activities were both impaired. None of the mutants could grow in nitrate-containing minimal media if $10 \mathrm{mM}-\mathrm{Na}_{2} \mathrm{MoO}_{4}$ was added.

\section{Nitrate reductase activity of mutants}

Mutant GY152 retained its 'respiratory' nitrate reduction ability but mutants GY154, GY156 and GY157 were affected in both assimilatory and 'respiratory' nitrate reduction.

Nitrate reductase activity of crude extract of $\mathrm{Rm} 41$ could be measured if sodium dithionite and methyl viologen (MV) were added as electron donor and carrier. This was also the case when cells were made permeable by CTAB treatment. The specific activity of MVcoupled nitrate reductase of CTAB-treated exponential phase cells of Rm41 was considerably increased when cells were grown with ammonium or glutamate or with nitrate plus glutamate (Table 3). Thus, MV-coupled nitrate reductase activity depends on the nature of the nitrogen supply to the cells; furthermore, nitrate is not essential for induction. Mutant $\mathrm{N} 461$, which is incapable of symbiotic nitrogen fixation (Kondorosi et al., 1973), had 30 to 100 times less MV-coupled nitrate reductase activity than the wild-type in all media tested (Table 3), although it could grow on nitrate minimal medium as well as the wild- 
Table 3. Methyl viologen-coupled nitrate reductase activities of mutants

Cells growing exponentially $\left(A_{540} 0.2\right.$ to 0.5$)$ in the media indicated $\left(\mathrm{NH}_{4} \mathrm{Cl}\right.$ and $\mathrm{NaNO}_{3}$ at $1 \mathrm{mg}$ $\mathrm{ml}^{-1}$ ) were treated with CTAB as described in Methods and assayed for methyl viologen-coupled nitrate reductase activity. Results are expressed as specific activities [nmol $\mathrm{NO}_{2}^{-}$formed $\mathrm{min}^{-1}$ (mg protein) ${ }^{-1}$.

\begin{tabular}{lcccc} 
Complete & GTS $+\mathrm{NH}_{4}{ }^{+}$ & GTS/glutamate & $\begin{array}{c}\text { GTS/glutamate } \\
+ \text { NO }_{3}^{-} \\
\text {Strain }\end{array}$ & \multicolumn{1}{c}{ Growth medium } \\
Rm41 & 1.47 & 13.80 & 23.40 & 42.40 \\
GY152 & 0.90 & 16.90 & 104.40 & 124.60 \\
GY154 & $<0.02$ & $<0.02$ & $<0.02$ & $<0.01$ \\
GY156 & $<0.01$ & $<0.01$ & $<0.02$ & $<0.01$ \\
GY157 & $<0.01$ & $<0.01$ & $<0.02$ & $<0.01$ \\
N461 & 0.046 & 0.24 & 0.22 & 0.43
\end{tabular}

type (Sik \& Barabás, 1977). This suggests that about $1 \%$ of the wild-type MV-coupled nitrate reductase activity is sufficient for growth on nitrate as sole nitrogen source. Mutants GY154, GY156 and GY157 had no MV-coupled nitrate reductase activity under any conditions tested, whereas mutant GY152 had a somewhat higher activity than the wildtype except in complete medium, suggesting that the mutation in this strain did not affect the structural gene(s) of nitrate reductase.

MV-coupled nitrate reductase activity in crude extracts of Rm41 and GY152 appeared in a single band after polyacrylamide gel electrophoresis (see Methods). As expected, extracts from GY154, GY156 and GY157 had no enzyme activity in the gels. Unfortunately, no protein band could be seen in the gel at the position of enzyme activity in the crude extract of Rm41 (data not shown). Therefore we could not conclude anything about the products of the nitrate reductase genes in the mutants.

\section{Xanthine dehydrogenase activity of mutants}

Mutants failing to utilize xanthine may be defective in the uptake system for xanthine and hypoxanthine or in xanthine dehydrogenase. These alternatives have to be distinguished. Xanthine dehydrogenase activity could be detected in wild-type and mutant strains by polyacrylamide gel electrophoresis followed by staining with $p$-nitrotetrazolium blue which is reduced to a brown-purple form by the enzyme (Fig. $3 a$ ). In this way, Rm41, GY152 and GY154 were shown to contain xanthine dehydrogenase activity but GY156 and GY157 did not. Small amounts of xanthine dehydrogenase activity could be demonstrated in gels from the crude extract of uninduced wild-type cells (data not shown). When gels were stained for protein (Fig. $3 b$ ), a sharp band appeared in the gels of the wild-type, GY152 and GY154 at the position of the enzymic activity. This protein band was not observed in gels of GY156 and GY157.

\section{Complementation analysis using mutant nit-1 of Neurospora crassa}

Mo cofactor preparations from various molybdo-enzymes can restore the nitrate reductase activity of extracts of the nitrate reductase-deficient mutant nit-1 of Neurospora crassa (Nason et al., 1970; Nason et al., 1971; MacGregor \& Schnaitman, 1972; Ketchum \& Downey, 1975). Extracts of Rm41, GY152 and GY154 possessed such Mo cofactordonating activity after acid treatment (Table 4), but GY156 totally lacked this activity. This suggests that either the structural gene for the Mo cofactor itself or its biosynthesis is impaired by the mutation. GY157 is also mutant for the Mo cofactor but it has some residual activity. 


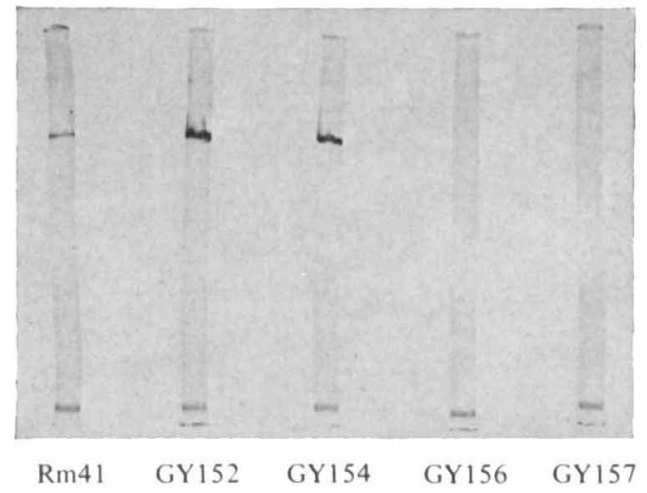

Fig. 3(a)

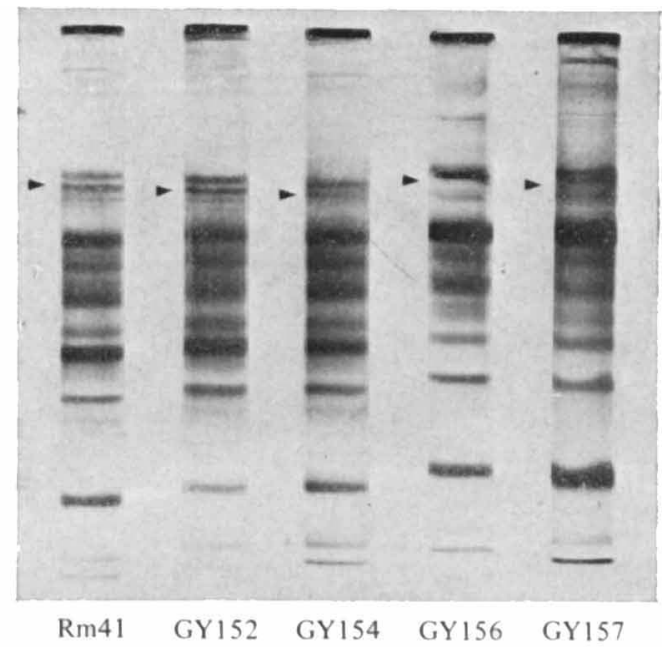

Fig. 3(b)

Fig. 3. Detection of xanthine dehydrogenase activity and its protein band in polyacrylamide gels. Rm41 and mutants were grown in GTS/glutamate medium supplemented with hypoxanthine $\left(1 \mathrm{~g} \mathrm{l}^{-1}\right)$ until late-exponential phase. Crude extracts were prepared and polyacrylamide gel electrophoresis was performed as described in Methods: $(a)$ gels developed for xanthine dehydrogenase activity; $(b)$ gels stained for protein (arrows indicate the positions of the xanthine dehydrogenase bands for Rm41, GY152 and GY154 and the equivalent positions for GY156 and GY157).

\section{Table 4. Complementation of nitrate reductase in extracts of mutant nit-1 of Neurospora crassa in vitro with acid-treated extracts of nitrate reductase mutants of $\mathrm{Rm} 41$}

Acid treatment and complementation analysis were carried out as described in Methods. Acidtreated extracts of $\mathrm{Rm} 41$ and mutants had no nitrate reductase activity in tests in which the extract of nit-I was omitted. The values represent the change in specific activity relative to that of the nit-1 extract.

$\begin{array}{cc}\text { Strain } & \begin{array}{c}\text { Restored nitrate } \\ \text { reductase activity }\end{array} \\ \overrightarrow{ } & 0 \\ \text { Rm41 } & 40 \\ \text { GY152 } & 40 \\ \text { GY154 } & 56 \\ \text { GY156 } & 0 \\ \text { GY157 } & 2 \cdot 1\end{array}$

\section{Symbiotic effectiveness}

All the mutant types were as effective as the wild-type in their symbiosis with lucerne seedlings (Fig. 4). Bacteria isolated from nodules retained their original phenotype. Thus, the effectiveness was not due to a reversion of the nitrate reductase mutation.

\section{Analysis of revertants}

Streptomycin-resistant derivatives were isolated from the mutants to provide an additional marker for identification. $\mathrm{Nar}^{+}$revertants of the streptomycin derivatives of GY152 and GY154 appeared on $\mathrm{FNO}_{3}$ plates at a frequency of $10^{-9}$ to $10^{-10}$, and those of GY156 and GY157, both showing pleiotropy, at the same frequency on $\mathrm{FNO}_{3}$ and $\mathrm{HYP}$ plates. In every case, the revertants regained the wild-type phenotype with respect to nitrate and hypoxanthine utilization, indicating that the pleiotropy was caused by a single point mutation in each mutant. 

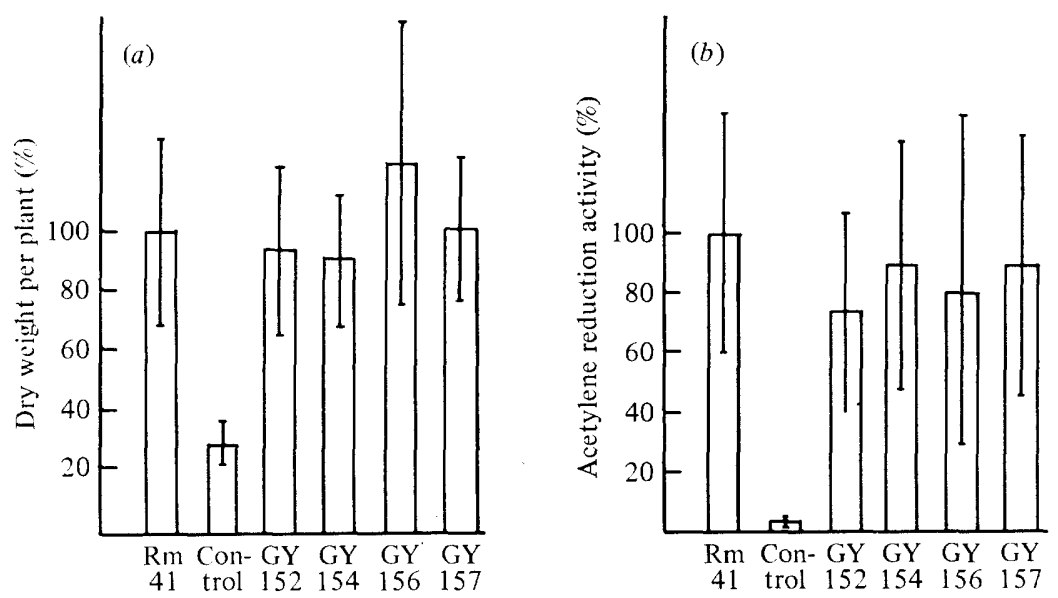

Fig. 4. Symbiotic effectiveness of wild-type Rm41 and its mutants. Plant nodulation experiments were performed as described in Methods. Ten plants were infected with each strain and infection was repeated at least three times. The bars (deviation from the mean) represent the $5 \%$ level of significance $(n-1=9)$. (a) Dry weight per plant, expressed as a percentage of the average dry weight of plants infected with wild-type bacteria. (b) Acetylene reduction activity, expressed as a percentage of the average wild-type activity.

\section{Genetic analysis of nitrate reductase mutants}

Plasmid R68.45 promotes chromosome transfer in Rm41 and has been used to establish the circular linkage map of this bacterium (Kondorosi et al., 1977a). To investigate the number of loci involved in nitrate assimilation, we first introduced R68.45 into auxotrophic derivatives of the three classes of nar mutants and performed crosses between these donors and a series of independent nar mutants with the same phenotype. Recombinants did not appear in crosses between GY75 (a met-168 derivative of GY152 carrying R68.45) and recipient mutants having the same phenotype as GY152. We therefore designate these mutants as narA. Similarly, recombinants did not appear in crosses between GY81 (a phe-15 derivative of GY154 carrying R68.45) and other independent mutants lacking only MV-coupled nitrate reductase activity. These mutants were therefore designated as nar $B$. However, recombinants did appear when GY248 (GY156 carrying R68.45) was crossed with eight out of eleven nar recipients having a pleiotropic phenotype. The eight mutants, including GY157, were designated as narD and the remaining three, including GY156, were designated as narC.

To localize the narB15 marker on the linkage map of the chromosome, auxotrophic derivatives of GY154 were used as recipients in mating experiments and linkage of auxotrophic markers with the narB15 marker was tested. We found that the narB marker was located between the trp-15 and ade-15 markers (Table 5, crosses 1 to 3 ). The location of the narD and narC genes was determined by a different approach. Plasmid R68.45 was introduced into GY157 (GY491) and was mated with AK351 and EV62. Counterselecting with streptomycin, selection was made for the ade-15 and $\operatorname{trp}-15$ markers, respectively, and the co-inheritance of the inability to utilize hypoxanthine was determined by replica-plating. Table 5 (crosses 4 and 5) indicates that narD was also located between the trp-15 and ade-15 markers. Crosses 6, 7 and 8 show the linkage data for the tyr-1, trp-15 and ade-15 mutations. We also observed that by crossing strain GY248 with EV62 the linkage frequency between trp- 15 and narB15 decreased from 57 to $0.057 \%$. When the same donor was crossed with AK351, no ade-15+ narB15+ recombinants appeared. This result indicates that the narB15 and narC191 genes are very close to each other and that narC191 is closer to ade-15. The map location of the nar genes is shown in Fig. 5; narA168 has not yet been mapped. 


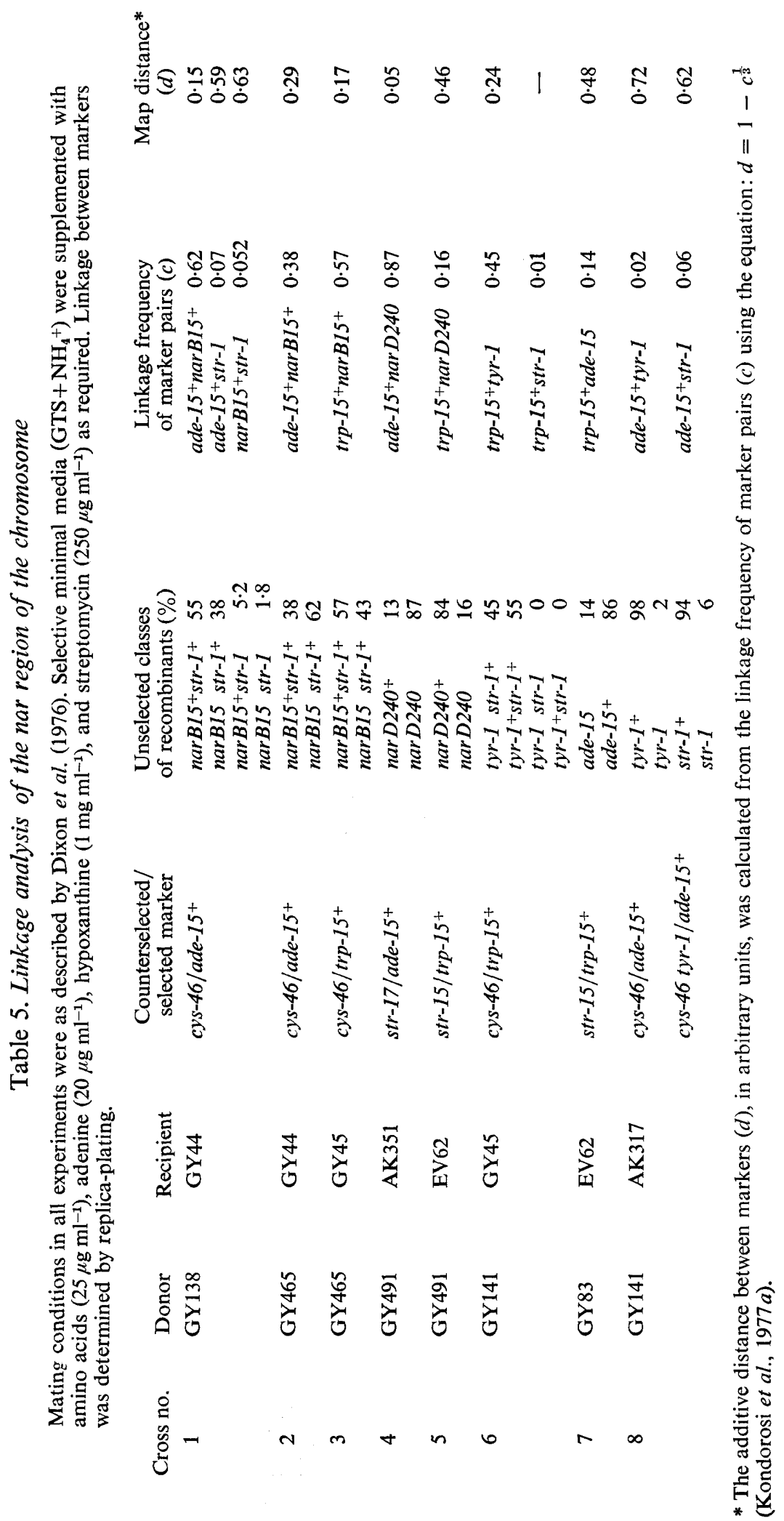



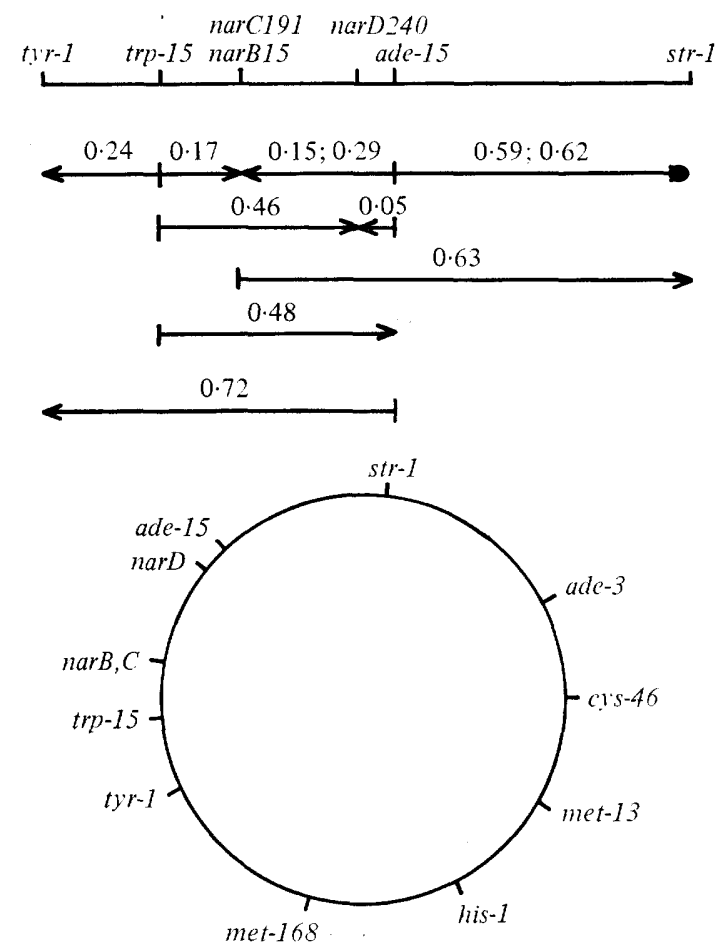

Fig. 5. Location of the nar genes on the Rhizobium meliloti 41 chromosome. Distances between markers are in additive map distance values $(d)$ (Kondorosi et al., 1977a) obtained from independent crosses. For details, see Table 5.

\section{DISCUSSION}

Of the two nitrate reduction systems demonstrable in Rhizobium meliloti in vivo, probably only the assimilatory type provides a basic physiological function. The role of the 'respiratory' system remains uncertain. A similar type of nitrate reduction activity with unknown function is induced during sporulation in Bacillus subtilis (Bohin et al., 1976). The induction of the 'respiratory' nitrate reduction activity in Rm41 resembles that of the respiratory system in Klebsiella aerogenes (Van'T Reit et al., 1968). However, the nitrate reductase activity of $\mathrm{Rm} 41$ is not affected by $10 \mathrm{~mm}$-chlorate and the enzyme does not seem to be membrane-bound (G. B. Kiss \& A. Kondorosi, unpublished work), suggesting that this nitrate reductase is similar to Pichinoty's B type enzyme (Pichinoty \& Piéchaud, 1968). If nitrate reductase is not membrane-bound, energy transfer may be prevented so that the organism cannot grow under anaerobic conditions. The activity and production of this enzyme in vivo were abolished by shifting the culture from anaerobiosis to aerobiosis. However, nitrite production started when anaerobic conditions were restored. This restoration of activity seems to demonstrate a preferential flow of electrons to oxygen under these physiological conditions.

Kondorosi et al. (1973) isolated mutants of Rm41 impaired in 'respiratory' nitrate reduction. Mutant N461 was ineffective in symbiosis but could grow on nitrate as sole nitrogen source (Sik \& Barabás, 1977). Therefore it must be normal in assimilatory nitrate reduction. We found that it had about 30 to 100 times less MV-coupled nitrate reductase activity than the wild-type in all media tested. Under conditions of nitrate assimilation even this low level of activity, however, could provide the cells with enough nitrite for maximal growth. The mutation in mutant N461 is believed to affect the regulation of nitrate reductase. 
Among mutants of $\mathrm{Rm} 41$ affected in aerobic nitrate assimilation, three phenotypic classes were observed. The class which we designate nar $A$ was unable to utilize nitrate, but was unaffected in 'respiratory' nitrate reduction in complete medium in vivo and MV-coupled nitrate reductase activity in vitro. Therefore it is likely that nar $A$ mutations do not affect the nitrate transport system but that the electron transport pathway of the nitrate reductase is impaired. We suggest that another electron transport pathway, independent of the electron transport chain to oxygen, is formed under conditions of nitrate assimilation, and these two pathways function independently. Presumably this alternative electron donor pathway is subject to regulation by amino acids and glutamine synthetase (Kondorosi et al., 1977b). The actual step in nitrate reduction measured as MV-coupled nitrate reductase activity was not controlled by ammonium since it remained derepressed in ammoniumcontaining medium.

A second type of mutation affected the MV-coupled nitrate reductase activity. Such mutants are defective in both assimilatory and 'respiratory' nitrate reduction, suggesting that the structural genes for the assimilatory and 'respiratory' nitrate reduction enzyme systems are common. The mutations may, for example, alter the structural gene of the nitrate reductase apoprotein.

The third phenotypic class of mutants, as represented by narC191 and nar D240, lacked both MV-coupled nitrate reductase and xanthine dehydrogenase activities. Reversion studies indicate that this pleiotropy was caused by a single point mutation in these strains affecting either the common regulation or the common structural moiety of these two enzymes. Since small amounts of xanthine dehydrogenase activity could be demonstrated in crude extracts of the uninduced wild-type bacteria (data not shown), but none in those from mutants narC191 and narD240 grown under conditions which induce xanthine dehydrogenase, the hypoxanthine transport system is probably not affected. Since both enzymes contain molybdenum, the mutants could be deficient in molybdenum assimilation. However, the activities of these nitrate reductase mutants were not restored by adding up to $10 \mathrm{~mm}$-molybdate, although such restoration has been reported with mutants of other microorganisms (Sperl \& DeMoss, 1975; Arst et al., 1970; Van Hartingsveldt \& Stouthamer, 1973). The narC and narD mutants had a biochemical phenotype similar to Mo cofactor-deficient mutants of other organisms (Pateman et al., 1964; Nason et al., 1970; Mendel \& Müller, 1978). The narA and narB mutants restored nitrate reductase activity to the Neurospora crassa mutant nit-1 in vitro, but nar $C$ and narD mutants could not. We suggest that $\operatorname{nar} C$ and narD mutants are deficient in Mo cofactor, although we have arso observed that both of these mutants apparently lack the xanthine dehydrogenase apoprotein. Possibly the absence of Mo cofactor could affect the stability or assembly of the apoprotein or its regulation. The previous results of Shah \& Brill (1977) and Pienkos et al. (1977) (see Introduction) agree with our results in suggesting that nitrate reductase and xanthine dehydrogenase share the same Mo cofactor and that this cofactor is not the precursor of the FeMo cofactor necessary for nitrogenase activity.

We have assigned 20 nar mutations to four genes, nar $A, B, C$ and $D$. Linkage data for nar $B$, nar $C$ and nar $D$ mutants indicate that these markers are located between $\operatorname{trp}-15$ and ade-15 on the Rm41 chromosome. The pleiotropic class of mutants lacking Mo cofactor activity was divided into two separate loci, $\operatorname{nar} C$ and $\operatorname{nar} D$, with $\operatorname{nar} C$ closely linked to narB.

Further study of the Rhizobium meliloti system should give us a better insight into the general nitrogen metabolism of this organism and its possible relationship with symbiotic nitrogen fixation.

We should like to thank Drs R. A. Dixøn, M. Gábor-Hotchkiss and Professor R. D. Hotchkiss for helpful criticism and correction of the manuscript and Dr P. T. Pienkos for providing mutant nit-1 of $N$. crassa. We are grateful to $\mathrm{K}$. Dobó for skilled technical assistance. 


\section{REFERENCES}

Arst, H. N. JR, MacDonald, D. W. \& Cove, D. J. (1970). Molybdate metabolism in Aspergillus nidulans. I. Mutations affecting nitrate reductase and/or xanthine dehydrogenase. Molecular and General Genetics 108, 129-145.

Bohin, J. P., Bohin, A. \& Schaeffer, P. (1976). Increased nitrate reductase $A$ activity as a sign of membrane alteration in early blocked asporogenous mutants of Bacillus subtilis. Biochimie 58, 99-108.

Bulen, W. A. \& LeComte, J. R. (1966). The nitrogenase system from Azotobacter: two enzyme requirements for $\mathrm{N}_{2}$ reduction, ATP-dependent hydrogen evolution, and ATP hydrolysis. Proceedings of the National Academy of Sciences of the United States of America 56, 979-986.

DAvis, B. J. (1964). Disc electrophoresis. II. Method and application to human serum proteins. $A n-$ nals of the New York Academy of Sciences 121, 404-427.

Dixon, R. A., Cannon, F. C. \& Kondorosi, A. (1976). Construction of a $\mathrm{P}$ plasmid carrying nitrogen fixation genes from Klebsiella pneumoniae. Nature, London 260, 268-271.

Hartree, E. F. (1972). Determination of protein: modification of the Lowry method that gives a linear photometric response. Analytical Biochemistry 48, 422-427.

Kennedy, C. \& Postgate, J. R. (1977). Expression of Klebsiella pneumoniae nitrogen fixation genes in nitrate reductase mutants of Escherichia coli. Journal of General Microbiology 98, 551-557.

Ketchum, P. A. \& Downey, R. J. (1975). In vitro restoration of nitrate reductase: investigation of Aspergillus nidulans and Neurospora crassa nitrate reductase mutants. Biochimica et biophysica acta 385, 354-361.

Kiss, G. B., Kondorosi, A. \& SvÁB, Z. (1977). Isolation and characterisation of assimilatory nitrate reductase mutants from $R$ hizobium meliloti. Acta microbiologica Academiae scientiarium hungaricae 24, 85 .

Kondorosi, A., Barabás, I., Sváb, Z., Orosz, L., SIK, T. \& Hotchkiss, R. D. (1973). Evidence for common genetic determinants of nitrogenase and nitrate reductase in Rhizobium meliloti. Nature, London 246, 153-154.

Kondorosi, A., Kiss, G. B., Forrai, T., Vincze, E. \& BÁNfalvi, Z. (1977a). Circular linkage map of Rhizobium meliloti chromosome. Nature, London 268, 525-527.

Kondorosi, A., Sváb, Z., Kiss, G. B. \& Dixon, R. A. $(1977 b)$. Ammonia assimilation and nitrogen fixation in Rhizobium meliloti. Molecular and General Genetics 151, 221-226.

Lowry, O. H., Rosebrough, N. J., Farr, A. L. \& Randall, R. J. (1951). Protein measurement with the Folin phenol reagent. Journal of Biological Chemistry 193, 265-275.

MacGregor, C. H. \& Schnaitman, C. A. (1972). Restoration of reduced nicotinamide adenine dinucleotide phosphate-nitrate reductase activity of a Neurospora mutant by extracts of various chlorate-resistant mutants of Escherichia coli. Journal of Bacteriology 112, 388-391.

MENDEL, R. R. \& MülleR, A. J. (1976). A common genetic determinant of xanthine dehydrogenase and nitrate reductase in Nicotiana tabacum. Biochemie und Physiologie der Pflanzen. 170, 538541.

MENDEL, R. R. \& Müller, A. J. (1978). Reconstitution of NADH-nitrate reductase in vitro from nitrate reductase-deficient Nicotiana tabacum mutants. Molecular and General Genetics 161, 77-80.

Nason, A., Antoine, A. D., Ketchum, P. A., Frazier III, W. A. \& LeE, D.K. (1970). Formation of assimilatory nitrate reductase by in vitro intercistronic complementation in Neurospora crassa. Proceedings of the National Academy of Sciences of the United States of America 65, 137-144.

Nason, A., Lee, K.-Y., Pan, S.-S., Ketchum, P. A., LAMBerti, A. \& De VRIES, J. (1971). In vitro formation of assimilatory reduced nicotinamide adenine dinucleotide phosphate nitrate reductase from a Neurospora mutant and a component of molybdenum-enzymes. Proceedings of the National Academy of Sciences of the United States of America 68, 3242-3246.

Nicholas, D. J. D. \& Nason, A. (1957). Determination of nitrate and nitrite. Methods in Enzymology 3, 983-984.

Pagan, J. D., Scowcroft, W. R., Dudman, W. F. \& Gibson, A. H. (1977). Nitrogen fixation in nitrate reductase-deficient mutants of cultured rhizobia. Journal of Bacteriology 129, 718-723.

Pateman, J. A., Cove, D. J., Rever, B. M. \& ROBERTS, D. B. (1964). A common co-factor for nitrate reductase and xanthine dehydrogenase which also regulates the synthesis of nitrate reductase. Nature, London 201, 58-60.

Pichinoty, F. \& PiÉchaud, M. (1968). Recherche des nitrate-réductases bacteriennes A et B: méthodes. Annales de l'Institut Pasteur de Lille 114, 77-98.

Pienkos, P. T., ShaH, V. K. \& Brill, W. J. (1977). Molybdenum cofactors from molybdoenzymes and in vitro reconstitution of nitrogenase and nitrate reductase. Proceedings of the National Academy of Sciences of the United States of America 74, 5469-5471.

SHAH, V. K. \& BRILL, W. J. (1977). Isolation of an iron-molybdenum cofactor from nitrogenase. Proceedings of the National Academy of Sciences of the United States of America 74, 3249-3253.

SIK, T. \& BARABÁs, I. (1977). The correlation of nitrate reductase and nitrogenase in Rhizobium symbiosis. In Recent Developments in Nitrogen Fixation, pp. 365-373. Edited by W. Newton, J. R. Postgate \& C. Rodriguez Barrueco. London: Academic Press.

SkotNICKI, M. L. \& Rolfe, B. G. (1977). Interaction between the nitrate respiratory system of Escherichia coli $\mathrm{K} 12$ and the nitrogen fixation genes of Klebsiella pneumoniae. Biochemical and Biophysical Research Communications 78, 723726. 
Spert, G. T. \& DeMoss, J. A. (1975). chlD gene function in molybdate activation of nitrate reductase. Journal of Bacteriology 122, 1230-1238.

Van Hartingsveldt, J. \& Stouthamer, A. M. (1973). Mapping and characterization of mutants of Pseudomonas aeruginosa affected in nitrate respiration in aerobic or anaerobic growth. Journal of General Microbiology 74, 97-106.

Van'T Reit, J., Stouthamer, A. M. \& Planta, R. J. (1968). Regulation of nitrate assimilation and respiration in Aerobacter aerogenes. Journal of Bacteriology 96, 1455-1464. 